\title{
2019 SEOM guidelines (the end of a decade)
}

\author{
A. González-del-Alba ${ }^{1}$ (D) Á. Rodríguez-Lescure ${ }^{2}$ (D)
}

Received: 21 January 2020 / Accepted: 21 January 2020 / Published online: 6 February 2020

(c) Federación de Sociedades Españolas de Oncología (FESEO) 2020

We present a new edition of the Spanish Society of Medical Oncology guidelines focused on reviewing the available evidence regarding the management of diagnosis and treatment in different tumors. Beyond the scope of a comprehensive review, the purpose of these guidelines is to provide an eminently practical view of the most relevant considerations with respect to the various cancer-related scenarios.

The first SEOM guideline on venous throboembolism and cancer was published in 2011; it was subsequently updated in 2014 , and, recently, greater insights into the physiopathological relationship between thrombosis and cancer have made it possible to conduct new studies that, together with the emergence of new oral anticoagulants, broaden the treatment options available to patients. A new update that examines the current evidence in this scenario is published in this issue [1].

Secondary prevention and evidence of the strategies defined for early detection of different tumors (breast, colon, cervix, prostate, lung, ovary, melanoma, and gastric cancer) are the object of review in this edition [2].

Germline mutation of the BRCA1 and BRCA2 genes account for the majority of cases of hereditary breast and ovary cancer; nevertheless, other genes have been identified as being involved. On the other hand, the emergence of PARP inhibitors in the treatment of cancer in BRCA mutation carriers entails implementing new models of genetic counselling and testing. This edition reviews the current clinical criteria for genetic testing, follow-up recommendations in healthy carriers, surgical risk reduction options and

A. González-del-Alba

aranzazu.gonzalezalba@salud.madrid.org

Á. Rodríguez-Lescure

alescure@geicam.org

1 Medical Oncology Department, Hospital Universitario Puerta de Hierro-Majadahonda, Madrid, Spain

2 Medical Oncology Department, Hospital General Universitario de Elche, Alicante, Spain new therapeutic strategies in cancer gene-mutated carriers [3].

The leading syndromes of hereditary predisposition for colon cancer are reviewed in this guide, paying special attention to the clinical manifestations that define them, their molecular features, the risk estimation associated with developing cancer, the most suitable risk reduction strategies, and surveillance recommendations [4].

Immunotherapy with checkpoint inhibitors has been shown to be effective in different types of cancer. Immunorelated side effects can be serious and life-threatening. To manage these drugs, in-depth knowledge is essential with respect to their toxicity profile and the target organs potentially affected, which allows for early diagnosis and pharmacological intervention [5].

The main steps forward being made in thyroid cancer are also updated in this issue. The histological profile, molecular classification, new diagnostic methods, surgical aspects, and leading systemic treatment innovations of this disease are widely reviewed [6].

In gastric and gastroesophageal junction cancer, breakthroughs in the knowledge of molecular biology are being translated into a therapeutic approach in advanced stages of the disease with overexpression of HER2. Furthermore, the authors of this guideline highlight endoscopic resection in early disease, the role of perioperative chemotherapy in locally advanced tumors, and the preliminary outcomes of immunotherapy in advanced disease [7].

For decades, scant inroads had been made with respect to small cell carcinoma of the lung. Recently, the addition of immunotherapy to standard platin-etoposide chemotherapy in first-line treatment has achieved significant benefit in overall survival. In recurring disease, new drugs, such as lurbinectedin and immunotherapy, are being investigated [8].

As for renal cell cancer, no adjuvant treatment has demonstrated a clear benefit for overall survival. In the setting of advanced disease, the combination of axitinib and pembrolizumab or avelumab in first line improves the efficacy data of sunitinib with greater overall survival for the combination with pembrolizumab. In intermediate risk patients or those 
having a poor prognosis according to the IMDC scale, the combination of ipilimumab-nivolumab enhances the overall survival compared to sunitinib. On the other hand, in patients who progress following one or two anti-angiogenic tyrosine kinase inhibitors, both nivolumab and cabozantinib increase overall survival in comparison to everolimus [9].

In cervical cancer, the clinical stage is the most relevant prognostic factor. The authors highlight the new 2018 classification of FIGO for staging that takes into account the status of lymph nodes. In recurrent or metastatic disease, the combination of chemotherapy and Bevacizumab is the treatment of choice. In recurrent disease after platinum treatment, immunotherapy with checkpoint inhibitors is emerging as the most promising option awaiting confirmatory results from ongoing studies [10].

\section{References}

1. Muñoz Martín AJ, Gallardo Díaz E, García Escobar I, Macías Montero R, Martínez-Marín V, Pachón Olmos V, et al. SEOM clinical guideline of venous thromboembolism (VTE) and cancer (2019). Clin Trans Oncol. 2019. https://doi.org/10.1007/s1209 4-019-02263-z.

2. Santaballa A, Pinto Á, Porta Balayà R, Ramírez Merino N, Ruiz Martín I, Saura Grau S, et al. SEOM clinical guideline for secondary prevention (2019). Clin Trans Oncol. 2020. https://doi. org/10.1007/s12094-020-02302-0.

3. González-Santiago S, Ramón y Cajal T, Aguirre E, Alés-Martínez JE, Andrés R, Balmaña J, et al. SEOM clinical guidelines in hereditary breast and ovarian cancer (2019). Clin Transl Oncol. 2019. https://doi.org/10.1007/s12094-019-02262-0.

4. Guillén-Ponce C, Lastra E, Lorenzo-Lorenzo I, Martín Gómez T, Morales Chamorro R, Sánchez-Heras AB, et al. SEOM clinical guideline on hereditary colorectal cancer (2019). Clin Transl Oncol. 2019. https://doi.org/10.1007/s12094-019-02272-y.

5. Majem M, García-Martínez E, Martinez M, Muñoz-Couselo E, Rodríguez-Abreu D, Álvarez R, et al. SEOM clinical guideline for the management of immune-related adverse events in patients treated with immune checkpoint inhibitors (2019). Clin Transl Oncol. 2019. https://doi.org/10.1007/s12094-019-02273-x.

6. Gallardo E, Medina J, Sánchez JC, Viúdez A, Grande E, Porras I, et al. SEOM clinical guideline thyroid cancer (2019). Clin Transl Oncol. 2019. https://doi.org/10.1007/s12094-019-02284-8.

7. Martín-Richard M, Carmona-Bayonas A, Custodio AB, Gallego J, Jiménez-Fonseca P, Reina JJ, et al. SEOM clinical guideline for the diagnosis and treatment of gastric cancer (GC) and gastroesophageal junction adenocarcinoma (GEJA) (2019). Clin Transl Oncol. 2019. https://doi.org/10.1007/s12094-019-02259-9.

8. Dómine M, Morán Bueno T, Isla D, Marti JL, Sullivan I, Provencio M, et al. SEOM clinical guidelines for the treatment of Smallcell lung cancer (SCLC). Clin Transl Oncol. 2020. https://doi. org/10.1007/s12094-020-02295-w.

9. Lázaro M, Valderrama BP, Suárez C, de-Velasco G, Beato C, Chirivella I, et al. SEOM clinical guideline for treatment of kidney cancer (2019). Clin Trans Oncol. 2019. https://doi.org/10.1007/ s12094-019-02285-7.

10. de Juan A, Redondo A, Rubio MJ, García Y, Cueva J, Gaba L, et al. SEOM clinical guidelines for cervical cancer (2019). Clin Trans Oncol. 2019. https://doi.org/10.1007/s12094-019-02271-z.

Publisher's Note Springer Nature remains neutral with regard to jurisdictional claims in published maps and institutional affiliations. 